\title{
A Picture is Worth a Thousand Words. On Photographs, Talking Contexts and Visual Silences
}

\author{
By \\ Mattias Frihammar
}

\begin{abstract}
This paper's point of departure is that historic silences are socially constructed and culturally productive, and that photographs in archives participate in the creation of historical silences despite, or maybe thanks to, their convincing depicting qualities. In this essay, photographs from three occasions have been studied in detail in order to elucidate different kinds of visual silences. The occasions are i) a funeral where it is the photographer's own mother that is being buried, ii) a funeral where the coffin is covered in a draping with a swastika, and iii) a royal funeral. Adopting a self-reflexive outlook, the purpose of this essay is to suggest a few possible ways of addressing silences that can occur when the presumptions of a beholder meet the image content of a photograph from the past. The three examples show that the concept of visual silence can be applied in different ways. In the first example, the technical and artistic shortcomings are interpreted as silencing components, which can convey information. In the second example, the (to a contemporary beholder) provocative silence around the historically charged symbol of a swastika becomes an analytical resource in its own right. The last example illustrates how a lot of information can compose such a dominant narrative, that it silences other stories.
\end{abstract}

Keywords: Visual silence, Photographs, Archive, Gunnar Lundh, Funeral, Media event.

Frihammar, Mattias: "A Picture is Worth a Thousand Words. On Photographs, Talking Contexts and Visual Silences", Culture Unbound, Volume 12, Issue 1, 2020: 217-232. Published by Linköping University Electronic Press: http://www.cultureunbound.ep. $\underline{\text { liu.se }}$ 


\section{Introduction}

Photographs have been said to be storytellers and memory mediums so persuasive that next to them, in the words of Allan Sekula, "all other forms of telling and remembering begin to fade" (2003:448). The technique in which an exposition of light leaves a trace on a photographic plate gives the impression that "the pencil of nature" captured the situation (Burke 2006:22). In this essay, I want to reflect on photographs as sources of cultural history knowledge and how they despite, or maybe thanks to, their supposedly unblemished depicting qualities, participate in the creation of historical silences.

Departing from the view that silence is "an integral part of processes of remembering" (Manson \& Sayner 2018:1), I want to test the concept of visual silences. How can the concept be understood? In what contexts does it appear? How can it be interpreted? The choice of concept is intentional. The search for silence will hopefully stress narrative aspects of visual mediums. Focusing on silence instead of, for example "lack" or "absence" implies that photographs, in singular but even more so as collected archives, contribute to the construction of historic narratives.

I understand visual silences as a result of the confrontation between the content of an image and the presumptions of a beholder. This calls for a self-reflexive approach. More specifically, it is the researcher's, meeting with, and interpretation of photographs that are of interest. After all, it is often through the work of researchers, such as myself, that photographs in an archive are found, highlighted, interpreted and explained before they become available to a museum audience.

The point of departure for this essay is my readings of a sample of photographs from the photographic archive of the twentieth century photographer Gunnar Lundh, which today is a part of the Nordic Museum archive in Stockholm. The motifs that the essay focuses on are thus part of a museum's collection. However, before they became museum items, they had travelled through a range of contexts. They first appeared as real-life situations during the first half of the twentieth century that the press photographer Gunnar Lundh found interesting. By pressing the shutter button on his camera, Lundh captured the reflections of the light inside his machine. Considering the camera body as context, the motifs were in an in-between pause; maybe this time the photographer had captured the perfect image, or maybe he failed to adjust the camera settings? The context changed again as the film rolls entered the photographic laboratory where, through the magic process of developing, two-dimensional images were integrated with three-dimensional papers, resulting in the physical presence of photographs. These (and their negative counterparts) were then incorporated into the archive of Lundh's image agency as glimpses of everyday life in twentieth century Sweden. 
In the image agency's commercial context, the images became commodities, ready to tell - and sell-their stories if an editor or journalist found them worth buying.

The context changed in a crucial way in 1961 when the archive was donated to the Nordic Museum in Stockholm. The move through space also meant a change in cultural value: the collection entered the realm of authorised heritage. In other words, the photographs became assets in a museum's production of knowledge about what history we share (Becker 1992). It is worthwhile to reflect on all of the contexts mentioned above when using historic photographs as sources of ethnographic knowledge.

The Lundh collection comprises more than 300000 individual photographs. The corpus covers the period from the early 1920 s to the late 1950s. The national context is Sweden, but there are also photographs from other European countries such as Denmark and Germany. Today, the Lundh collection constitutes approximately one-fifth of the Nordic Museum's total photographic collection. The collection is characterized by heterogeneity in its motifs, reflecting both topics that interested Lundh personally and motifs he thought he could sell within a media context.

One purpose of Images and Stories of Everyday Life, the umbrella project in which this essay is produced, has been to digitise a considerable amount of Lundh's photographs. Therefore, the lion's share of the photographs was initially scanned at low resolution and the seven researchers involved were asked to select motifs based on their respective research interests. The selected pictures were scanned in a higher quality and published online. The idea behind this procedure was that each researcher would produce valid and serviceable metadata guided by his or her own scholarly expertise.

Being an ethnologist who uses qualitative methods, one issue for me was to address such a massive and varied corpus of pictures as presented by the Lundh collection. As I skimmed through all the pictures, I noticed that funerals were, if not frequent, at least a regular feature in the collection. Based on this observation, the choice was made to let my scholarly interest in social and cultural constructions around death govern the selection process. ${ }^{1}$ My answer to the project's call to select photos thus resulted in a selection of pictures of funerals and burial ceremonies, totalling just under 500 pictures from approximately 30 events. It is from this sample that photographs of three funerals were chosen for this essay. The analyses of the three cases will be presented in turn. Each example begins with a description of the sample of photographs and a review of what the images represent, followed by my reflections and lines of thought throughout the analysis. 


\section{Close Reading of Silent Talking Contexts}

Eighteen pictures of a funeral. Five of them in a church environment and nine of a grave covered in flowers. Four depict people in dark clothes. What story can the pictures tell? The objective in this example is to demonstrate how a narrow reading can uncover new, unexpected clues, which in turn may reveal layers of articulations in otherwise apparently silent photographs. Let us start with the photos of the coffin in the church.

One shows flower bouquets and wreaths arranged on top of, and in front of a coffin or placed on either side of it along the walls. White ribbons are hanging from some wreaths, but it is not possible to see what they say. The blurry head of a person standing behind the coffin, and wearing a black top hat is visible in one picture. The focus of the camera has not been adjusted properly.

I saw that the photos depicted a funeral. Yet, they seemed difficult to interpret: who was dead, who was mourning, and what should the observer think about it? There were no crying eyes, no wet handkerchiefs, no bowed heads, and no one to identify with. The man behind the coffin appeared almost like a ghost due to the blurry quality of the photo. Despite the emotive motif, the pictures appeared bland, or visually silent. They did not speak to me. However, a photograph is not only an image but also a material object. A photograph in an archive is more than a singular physical thing; it is an object in a particular context. In this example, the contiguous context was a so-called contact sheet on which the photograph was mounted. On the cardboard sheet there was an ornate handwriting reading "Gunnar Lundh's mother's funeral in Höganäs church".

The note added information; the pictures were shot in a church in Höganäs in the south of Sweden. However, it also said something about the social context: the photographer and the person being buried were mother and son. With this knowledge, the visual elements and the poor technical quality started to speak to each other. Even though the contours and content were the same, I read them in new ways. For example, I saw the blurriness as an expression of an emotionally affected photographer. The unengaged composition made me reflect on the touching aspects of a man taking photographs at his mother's funeral.

Taking a self-reflective perspective, I noticed that my gaze changed when I became acquainted with the social context of the situation. I started to look at the pictures as if they were part of a family album, instead of the museum's archive. Family photo albums are about emotional communication and can reflect individual ways of grasping and handling challenges in life (Sandbye 2014, see also Dahlgren 2013 and Batchen 2008). My new, more personalized gaze allowed me to read between the lines.

This kind of personal reading may seem academically unconventional. However, Lundh's business was rather small. Apart from occasional assistants, he 


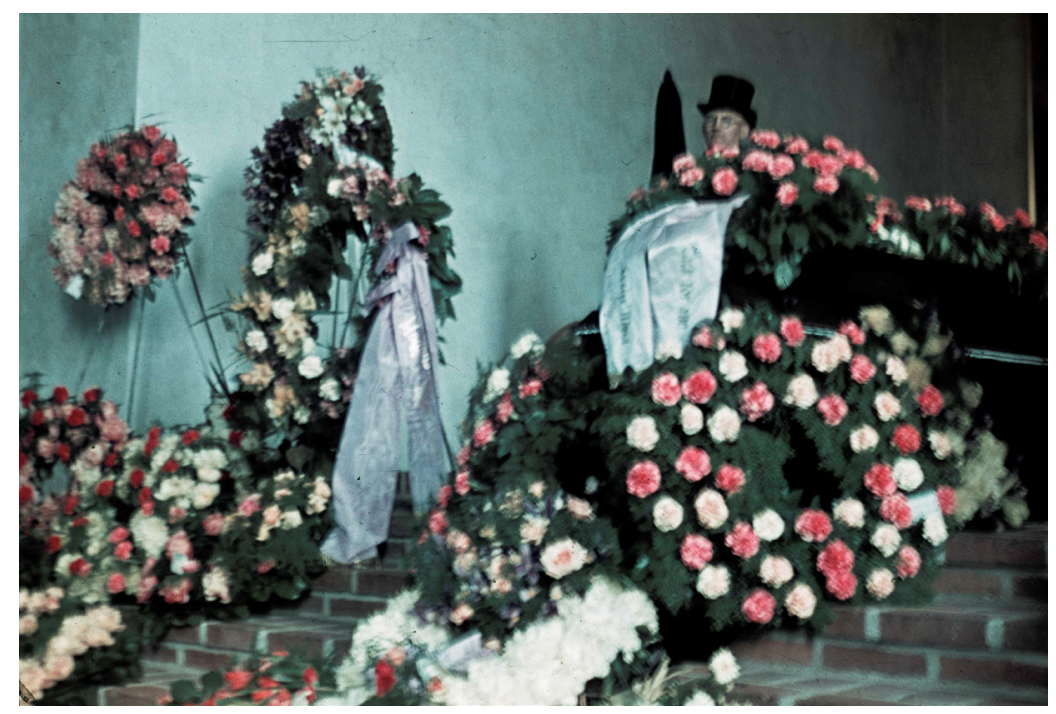

Fig. 1 Photo Gunnar Lundh (NMA.0045731).

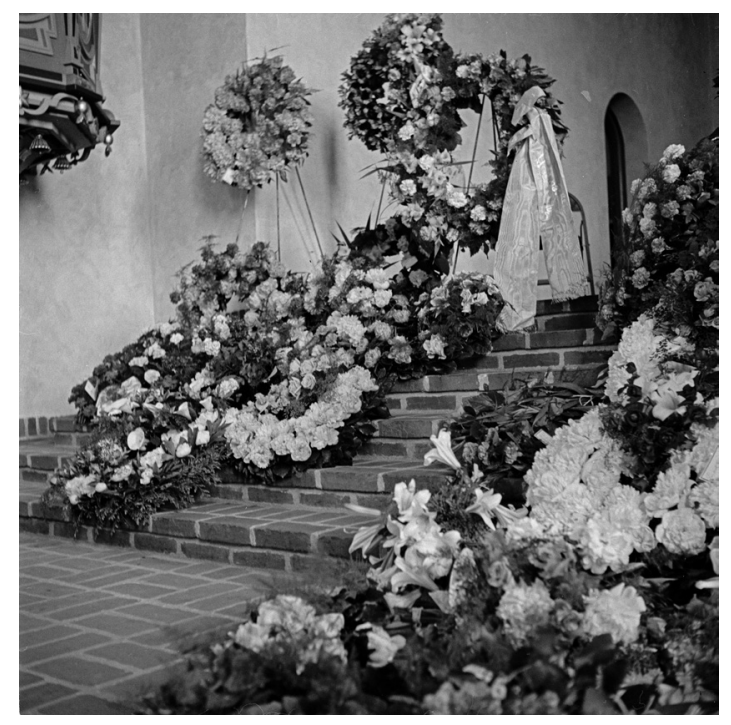

Fig. 2 Photo Gunnar Lundh (NMA.0094381).

took care of the business himself-eventually together with his wife, and stored all copies and negatives at home. The indexical relation between the auteur and his work was utterly robust, and my intimate interpretation seemed to allow for a new understanding of the material. On the other hand, these were not photographs in a private family photo album but, rather, official records in the museum's archive. 


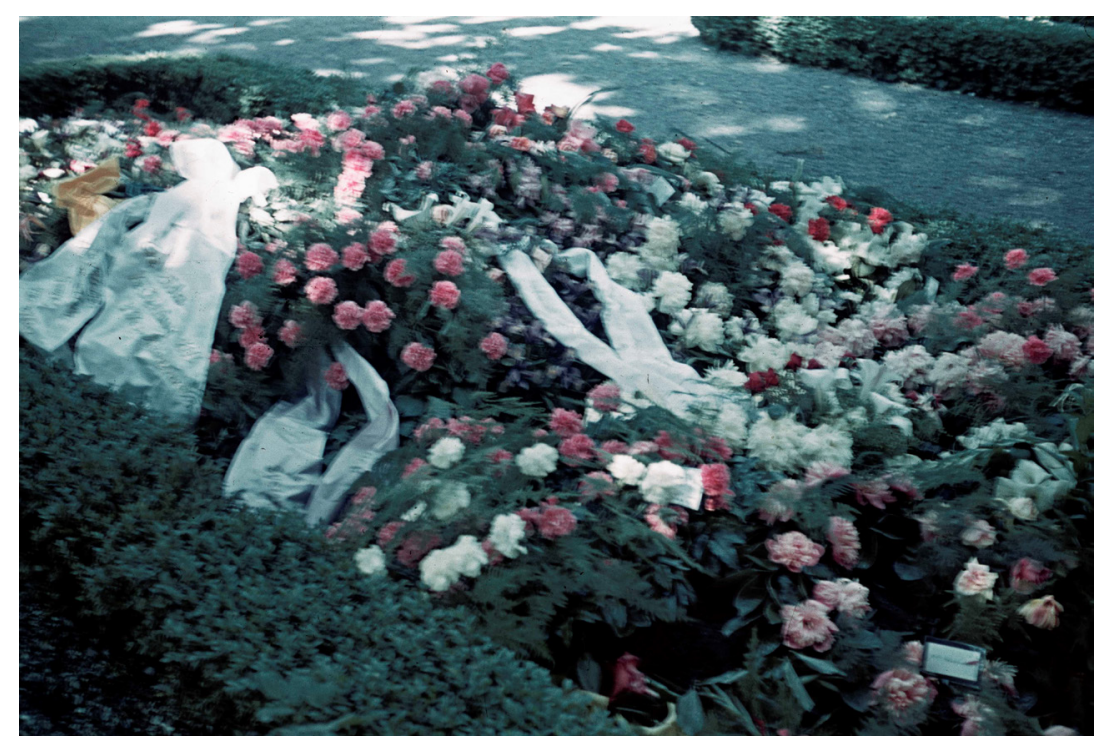

Fig. 3 Photo Gunnar Lundh (NMA.0045742).

As such sources, they reached further than the individual creator, representing not only Lundh but also the official memory of the institution. This called for a distant and critical perspective in the analysis.

The two ways of approaching the photographs may seem incompatible. The answer was to oscillate between the two perspectives and let the knowledge of the personal context highlight the universal side of the situation, and vice versa. By allowing myself to become emotionally engaged, the affective qualities made the photos generally interesting as micro-historic sources. Put differently, allowing a personal relationship between the photographer and the photographed to be included in the analysis made the blurred images tell a story.

As a consequence of including the photographs from Lundh's mother's funeral in this article, they have been published on the internet through the umbrella project. They are now generally accessible, and through the museum's work, information is linked to the pictures to explain the context. However, the detail that made me see the pictures in a new light will not be accessible to online viewers; the expressive handwriting will stay on the contact sheet.

\section{Symbols that Scream Versus Silences that Speak}

What I perceived as a visual silence in this next example was the contrast between a highly politically laden occasion and the evidently modest documentation of it. While the other funerals were often documented in many photos, there was only 
a single picture. The motif is the interior of a church, taken from a bird's-eye-view. The spectator looks down at a hall where a service is taking place. You see the church's quatrefoil choir window, a chandelier, and small birch trees along the walls. Constituting the centre of the photograph is a coffin. On each side are three candlesticks with burning candles. People are sitting on the church benches. Five people are standing up, two on each side of the coffin and one at the end of it, each one holding a banner. However, what made me inspect the picture more thoroughly was the draping of the coffin. A cloth with a large swastika, the Nazi symbol, was covering it.

I found only one shot from this occasion. However, like the other photos, this photo is mounted on a contact sheet. Nine photos show interiors from what might be Lundh's apartment, which also functioned as his office and lab. Five include people performing work-related practices. One photo represents a flower pot in a window, another the exterior of a white house on a snowy street. It is a rather odd collection of motifs. The sheet is marked with the year 1934. There are some handwritten notes: at the top it says "Gunnar Lundh's laboratory", and to the right, "Stockholm". Under two pictures, the initials "G.L." (Gunnar Lundh?) and the names "R. Hallin" and "Flodin" are found. On the one hand, this solitary funeral photo could easily have been overlooked. On the other hand, the symbol on the coffin cried out as a punctum (Barthes 1993). What appeared to me as visual silences, were firstly the fact that there was only one picture of this occasion, and secondly that the picture with the symbol of a swastika was presented without comment.

My initial thought was that the photos on the sheet were shot in chronological order during one day. Following this hypothesis, Lundh would have shot some working scenes in the morning, then documented the funeral, taking a photo of the white house in passing. Back at the office in the afternoon, he would have continued to work with the working scenes and eventually shot the photo of a plant in a pot. I scratched my head, as I tried to find the logic in the photographs.

However, according to a colleague ${ }^{2}$, the photos were probably taken at different times and places. Due to my knowledge that Lundh had accompanied the Women's Section of the Social Democratic Party on a trip to Germany during winter 1934, I tried the hypothesis that the photo was shot in Germany. As a consequence of changing the national context, the Nazi symbol did not appear as piercing as before. In 1933, the flag with the swastika had become the national flag of Germany, and had a double meaning, representing both the Nazi party in Germany and the German nation state.

My initial encounter was with a small photo glued to a contact sheet. When it was scanned at high resolution, it became possible to read Swedish words on the banners, pointing towards a Swedish context after all. My attentive colleague offered a new theory: maybe it was the remains of Carin Göring, the late wife 


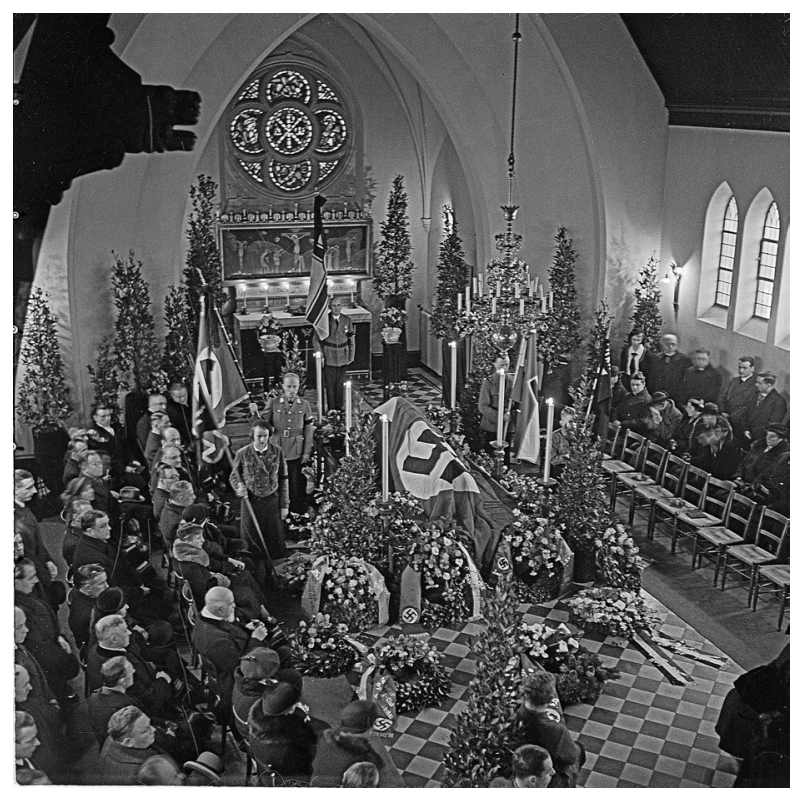

Fig 4. Photo: Gunnar Lundh (NMA.0094380).

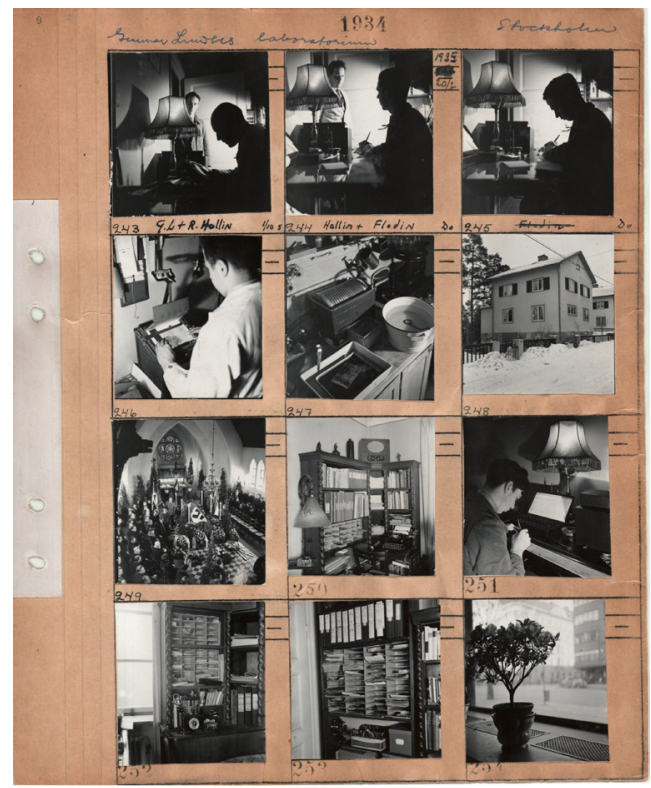

Fig. 5 Photo Gunnar Lundh (NMA.0082523).

of Herman Göring, commander-in-chief of the German air force, the Luftwaffe, inside the coffin. ${ }^{3}$ The theory was supported by the year, the Nazi symbols and the official character of the ceremony, but most of all by the suspicion that the location 
was Oscars Lillkyrka (Oscar's Church) in central Stockholm, located in the same neighbourhood as Carin Göring's family.

If the theory was correct, the photo could alter the historiography of Sweden's Nazi connections before the war. It would perhaps be possible to identify politicians or other high-ranking individuals attending the ceremony. The new circumstances led to an increased eagerness to know more. A first step was to identify the location, and, keen on getting a result, I rapidly consulted colleagues with competence in architecture. After a while, the conclusion was that the photo was shot in Sandsborg Chapel at Sandsborg Cemetery, located a few kilometres south of Stockholm. ${ }^{4}$

This new and solid information did not support the Göring hypothesis. It is unlikely that such a high-profile ceremony would have been conducted outside Stockholm at a place with no connection to the deceased, and I found no other information about any ceremony taking place in Sweden backing the theory. ${ }^{5}$ With this information, my interest in the photo declined. It is worthwhile to linger on my own fluctuating interest in the photo. What I saw at first was a photo of a funeral ceremony (of which I had seen quite a few by Lundh) with a detail that struck me as provocative. The thing that stood out, of course, was the swastika.

When I first placed the photo in a Swedish context, it roused my attention. The assumption that the photo was shot in Germany made the interest fade. When it then seemed as the picture was shot in Sweden after all, it started to tease my mind once more. When the connection to Göring came up, I even engaged several colleagues in the process of identifying the site. My interest faded again when the Göring connection seemed to be too flimsy to be taken seriously. Taking a reflexive stance, I recognize that the presumptive connection to high politics made me a bit too enthusiastic, and I missed the crucial point that Lundh put this photograph side by side with photos of everyday situations such as work in the laboratory, a house in the street and a flower pot.

Lundh did not mark or comment on the photo. This suggests that neither the swastika nor Nazism stood out as remarkable to him. Lundh had been working in Berlin (without expressing any sympathy for the Nazi party or ideology) and had most likely encountered the symbol in various contexts. In Sweden, Nazi sympathies were growing: two years after the date of the photo, the Nazi party was at its height in Sweden and received over one hundred mandates in the municipal elections (Lööw 2004: 244). Nazi ideology was part of political life, at least at a regional level in Sweden at the time (ibid: 9). As a whole, Lundh's archive reflects this: visual representations of Nazism are regular features in the collection.

However, the analytical potential of photos representing Nazi symbols is not that they prove the presence of Nazi ideology in Sweden at the time, but rather 
that the expression of Nazism was a banal element to the auteur. Therefore, it is crucial to comprehend the silence surrounding the photo of the Nazi funeral as a historic source in its own right. This kind of visual silence reflects a society in which Nazi ideology was taken as an ordinary component. This interpretation was lost in the enthusiasm over a chance to place an unknown piece into the historic puzzle.

The swastika was not an innocent symbol at the time; the Nazi ideology was available to be read, even if the symbol had not yet been charged with the crimes committed by the Nazi regime in the subsequent decade. A lesson to be learned from this example is that destructive or totalitarian regimes do not advertise in advance. Once again, the potential is in the contexts: it is in relation to other photos that the silence can be identified, and this can only happen if the contact sheet is kept intact. This will be a challenge in the process of digitalization, where each photo is scanned as an individual image; a person who comes across the photo online will not see it side by side with a flower pot and an average house in the street.

\section{Contemporary Silence of Historic Media Noise}

The photos of the third funeral contrast with the two others concerning milieu and number. There are also many other sources for the same event, which makes it interesting to reflect upon what silences that are re-produced. There are more than 60 photos shot in a couple of sequences. I will briefly account for them in the chronological order in which I presume they were shot.

Three photos show a parade of more than 50 people in black coats and top hats. The next few shots capture black cars sequentially parking outside a massive entrance of what appears to be a church. Even if none of the pictures capture the whole building, the church in question appears to be impressive. One picture shows a row of flagpoles with flags at half-mast. The weather is cloudy, and there are patches of snow on the ground.

Another suite of photos shows a coffin being carried out from the entrance. The bearers are men in military uniforms. Men wearing dark overcoats and top hats appear to assist them. Spruce branches cover the ground next to a small wooden staircase placed in front of a catafalque. A number of uniformed mensoldiers-wearing tall fur caps are standing in rows, at attention, rifles with bayonets pointing straight up. The camera's eye is directed towards the coffin, and when the catafalque eventually leaves, the viewer can follow it as it disappears between impressive façades that a Stockholm native would recognize as the Royal Castle in Stockholm. Behind the uniformed guards, several attendees carry still or movie cameras. More photos show people emerging from the entrance and getting 


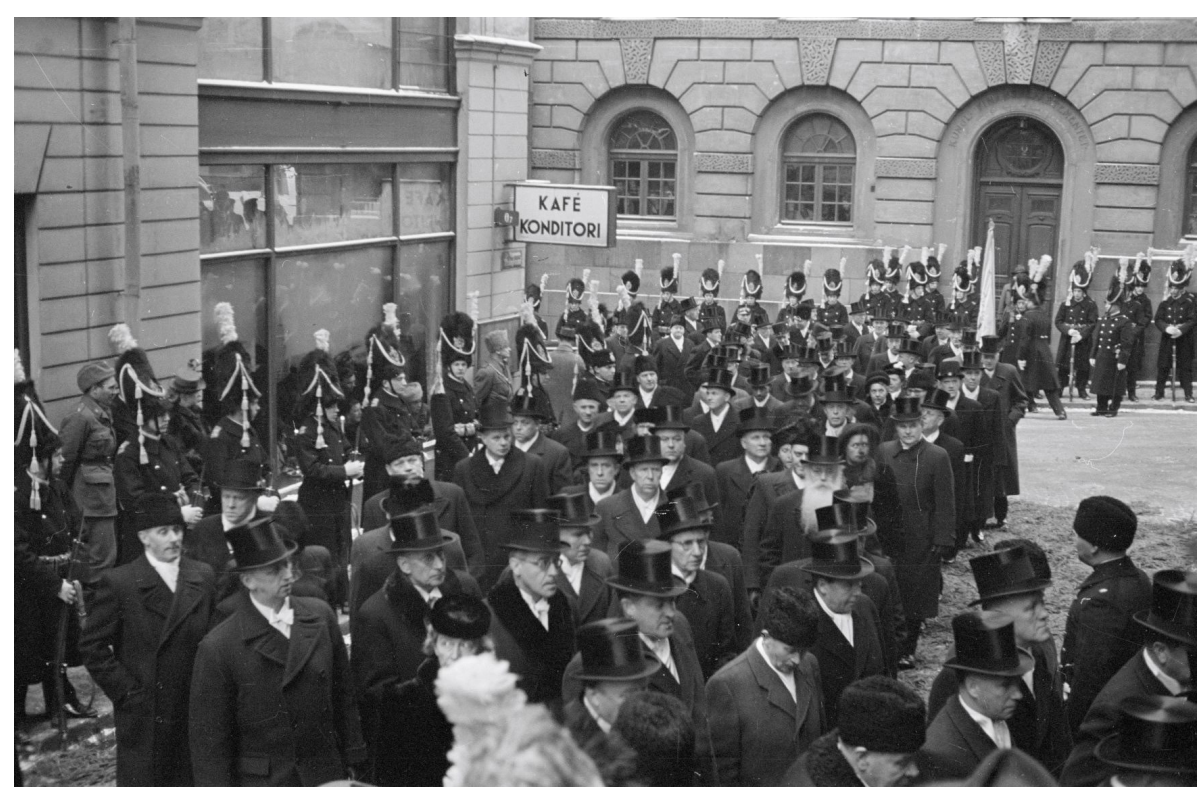

Fig. 6 Photo: Gunnar Lundh (NMA.0094382).

into a black car. Those familiar with the Swedish royal family will recognize Gustaf Adolf, who was the crown prince of Sweden at the time (eventually king Gustav VI Adolf). The woman by his side is harder to recognize; a mourning veil covers her face. Given the situation, it is most likely the crown prince's wife Louise. Another picture captures three young girls walking down the stairs, followed by an older woman. These are three of the four princesses with their, at the time well known, nursemaid Ingrid "Nenne" Björnberg. The fourth sister and their little brother, Carl Gustaf, are absent.

Another sequence depicts six horses pulling the catafalque through a street lined with people. In the same series, a long cortège of black motor cars is eventually visible. People have gathered in the streets. However, despite the crowded pavement, the impression is that all is quiet and disciplined. In contrast to the other two funerals, this one is easily put into its historical context. It is the funeral of an official person in Sweden, Prince Gustav Adolf (not to be mistaken for his father and namesake, Prince Gustav Adolf, mentioned above), the father of the present King Carl XVI Gustaf (who is the princesses' little brother, also mentioned above). The death of the prince was unexpected; he was killed in an airplane crash on January 26 in Copenhagen. He had a state funeral. The church in the photo is Storkyrkan, the Great Church, in Stockholm. The year was 1947.

The royal funeral was an official occasion and of great public interest. It thus constituted what Dayan and Katz call a media event (1992). A media event is organized with a high degree of consideration for the needs of the media. First, journalists and photographers (still, film and broadcast) are guaranteed good 


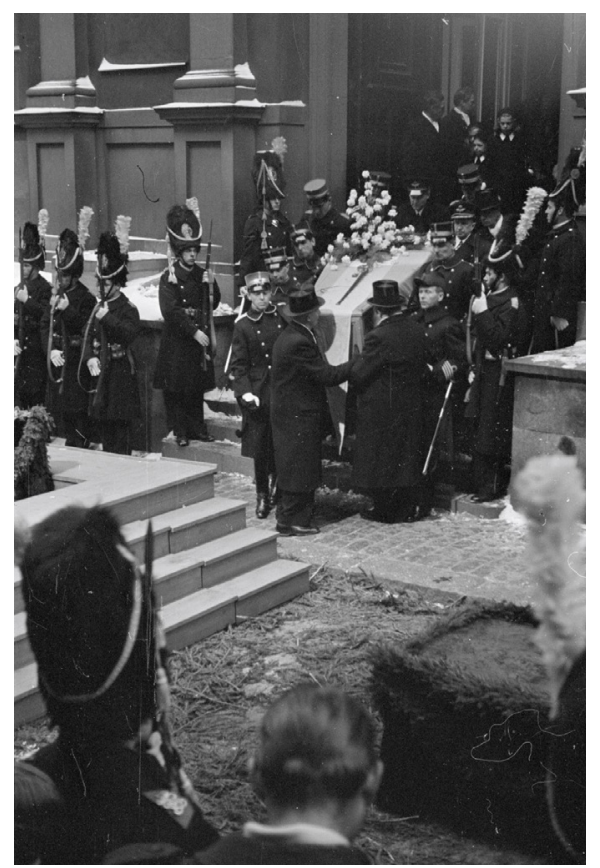

Fig 7. Photo: Gunnar Lundh (NMA.0094382).

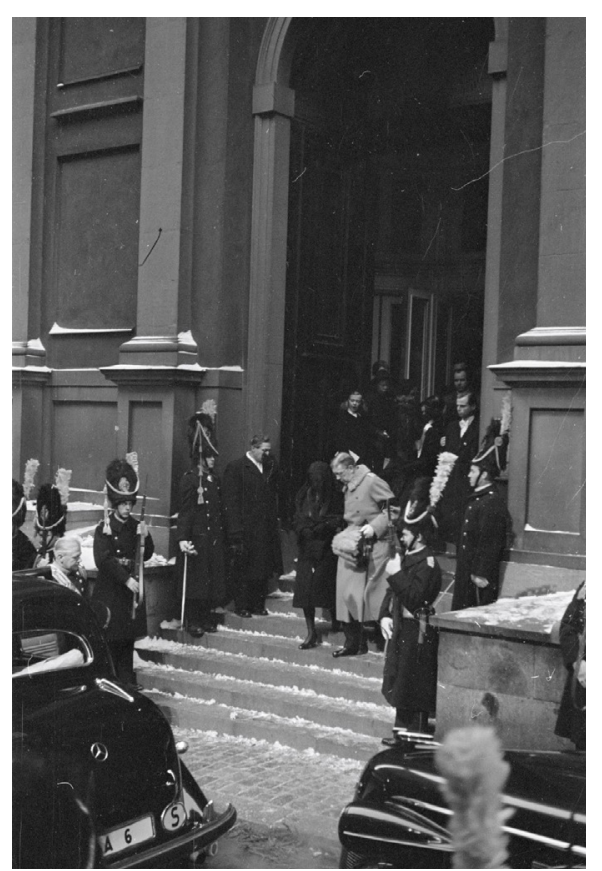

Fig. 8 Photo: Gunnar Lundh (NMA.0094382).

views. Second, media events are designed to be as photogenic as possible. Third, the activities are organized at a time for the best possible medial dramaturgy. One of Dayan and Katz's arguments is that the recognizable script creates a sense of redundancy, and the audience identifies the event as something important.

Scrutinizing the photos from the prince's funeral, the contours of the media event are recognized. The photos are shot from a close and elevated location, giving full visual access to the entrance of the church (my guess is that other press photographers are standing in the same spot as Lundh). The stairs to the church serve as a stage where various prominent people are put on display for the best photogenic scene. Every viewer familiar with societal hierarchies and the repertoire of funerals will understand that this is a funeral of a significant person. The short, predetermined path frames the event as important and sorts the participants by rank; some are watching, while others are being watched. The social ranking is documented and reproduced in Lundh's photographs.

It has been argued that one of Lundh's qualities as a press photographer was in capturing unspoiled extracts from ordinary people's everyday lives giving otherwise unheard voices an opportunity to speak (see, for example, the contributions of Steinrud, Bäckman, Hörnfeldt and Larsson to this issue of Cultural Unbound). Lundh's interest in the everyday offers insight into ordinary 


\section{Culture Unbound}

Journal of Current Cultural Research

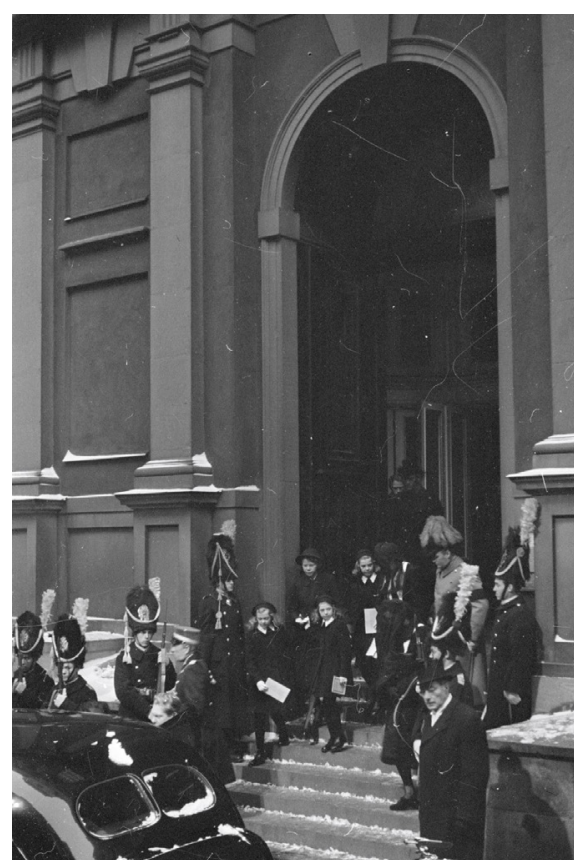

Fig. 9 Photo: Gunnar Lundh (NMA.0094382).

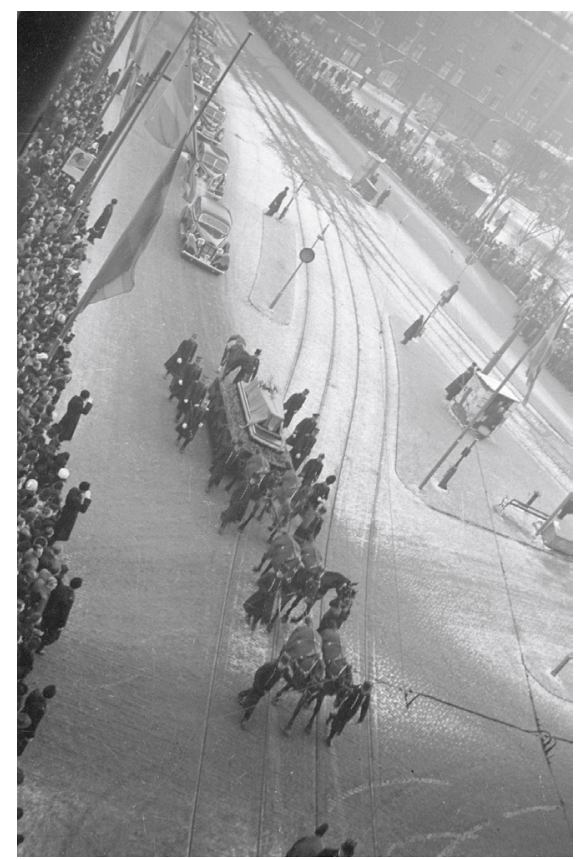

Fig. 10 Photo: Gunnar Lundh (NMA.0094382).

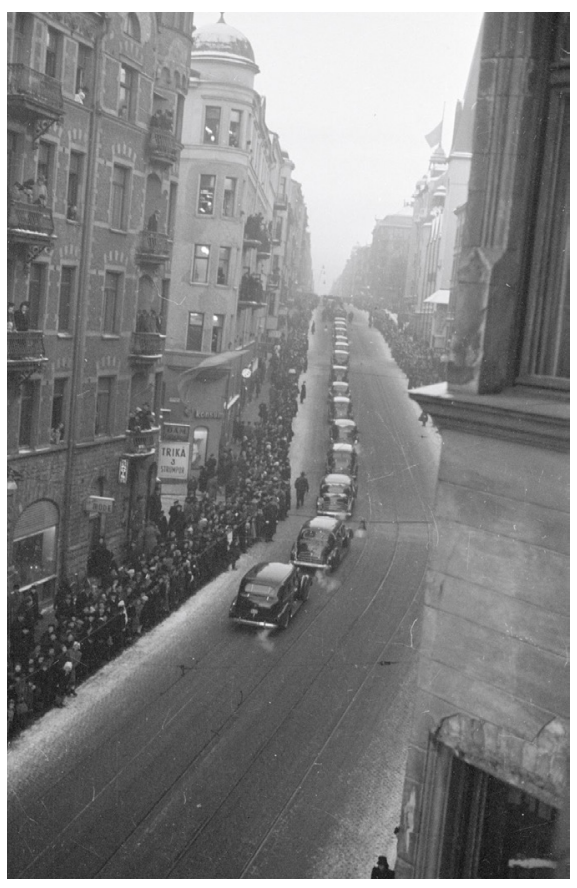

Fig. 11 Photo: Gunnar Lundh (NMA.0094382). 
people's lives, otherwise absent from historical records. This documentation, on the other hand, echoes official historiography more than it contributes to a new understanding of the past. Documenting the royal funeral, Lund is captured by the logic of the media event. The pictures join in a symphony that is orchestrated by the those in power and thus silences other narratives.

In the archive, this photographic suite belongs to the same genre as the photos of the funerals of other prominent individuals, such as Archbishop Nathan Söderblom in 1931; the former Prime Minister and Marshal of the Realm, Oscar von Sydow, in 1931; Prince Eugene in 1947; and two famous actors, Gösta Ekman in 1938 and Anders de Wahl in 1956. The effect of the digitalization of photographs representing well-known historic events is hard to evaluate. In the case of the funeral of Prince Gustav Adolf, as with the other funerals of prominent persons, a qualified guess is that these will reach an interested audience and, as a kind of resonance, strengthen an already established historical narrative.

\section{Concluding Reflections}

In examining Gunnar Lundh's archive, I have treated photographs not as nouns but as verbs, as entities that do something. One conclusion is that visual silence is neither absolute nor predictable. The blurry photos in the first example were silent until the intimate context became clear to me, then the technical and artistic shortcomings started to convey information. The silence of the lonely photo of the Nazi funeral in the second example turned out to be an important resource in its own right. The last example illustrated how a massive amount of information can compose a dominant narrative that silences other narratives.

A final meta-reflection can be included. The large amount of digitized images published online through this project will generate new stories about the period when Gunnar Lundh was active. There has been considerable discussion about the consequences of digitalization in relation to the responsibility of heritage institutions. One side points to a democratic aspect of digitalization with the photos becoming available to an infinite number of people. The more sceptic side points out ethical issues and copyright issues, among other things.

Nonetheless, there seems to be an agreement that when something is digitized and published online, the original institution loses control. However, losing control does not necessarily mean that knowledge production decreases. Cecila Strandroth has shown how unnoticed photos in the archive suddenly gained a great amount of interest when published online. Previously anonymous photos began to be downloaded and discussed, adding both knowledge and context to the photos (2012: 109ff). 
Digitization can open up new ways of understanding historic photographs. However, reflecting on the examples in the article, it may also underpin representational biases instead of challenging them (see for example Taylor \& Gibson 2017). Pictures from a royal funeral might find a wide audience, since the narrative is already part of a collective memory. Photos representing an anonymous funeral may fade away into a collective amnesia.

A picture is worth a thousand words. By offering a multitude of pictures of everyday life as seen through the eyes of Gunnar Lundh, hopefully the project Images and stories of everyday life will contribute to a nuanced conception of the past. However, what narratives and whose memories that may fade away in the process is impossible to say in advance. There is the oft-quoted saying by Søren Kierkegaard, that life can only be understood backwards, but it has to be lived forwards (Kierkegaard 1843). The same principle goes for a research project: first you have to do it, then you can evaluate it. If nothing else, the variety and number of motifs remind us that the past is neither a single nor a coherent story but rather a whirlwind of different destinies with individual joys and sorrows.

Mattias Frihammar is an ethnologist at the Department of Ethnology, History of Religion and Gender Studies (ERG) at Stockholm University. He is initiator of the Critical Heritage Studies Network at Stockholm University and coordinator of the Bachelors Program in Museum and Heritage Studies at Stockholm University. He is currently involved in the research project Making a Military Heritage: Gender and Nation in Sweden's Cold War History. This article is part of the project Images and Stories of Everyday Life (Vardagens bilder och berättelser), financed by The Royal Swedish Academy of Letters, History and Antiquities, and The Swedish Foundation for Humanities and Social Sciences. Email: mattias.frihammar@ etnologi.su.se

\section{Notes}

1The choice of motifs can be said to be analytically motivated, as the practices around death mirror a society's cultural structure (Durkheim 1915). However, the main point is the universality of death. Death concerns, affects and strikes everyone. Everybody will eventually die, regardless of gender, class or race. A sample of funeral photos therefore opens up a discussion about what identities will become part of a collective memory. Everybody dies, but whose deaths are remembered? Whose deaths are left in silence?

2 An important person for my research process in this project, and for the research project as a whole, is the photographer Per J. Larsson. Larsson has been in charge of scanning the photographs of Gunnar Lundh. Larsson has become very familiar 


\section{Culture Unbound}

Journal of Current Cultural Research

with the collection and has a comprehensive view of Lundh's work, which has been of great value to the researchers. Larsson has also contributed reflections and forward-looking proposals on how to understand the collection throughout the project. Among other things, it was Larsson who informed me of the fact that Lundh sometimes collected motifs from different occasions on the same contact sheet and identified the funeral with the Swastika as having taken place in Sweden. 3 Carin Göring died on October 17, 1931 and was buried outside Stockholm at Lovön. After her death, Göring built a hunting lodge in Germany called Carinhall in honour of his late wife, and in the beginning of summer 1934, Carin's remains were moved from Lovön in Sweden to Carinhall in Germany.

4 Thank to Fredrik Krohn Andersson and Peter Gillgren for helping me identify the chapel.

5 In Germany, on the other hand, the funeral of Carin Göring was arranged in a statesmanlike manner and broadly broadcasted by the Nazi propaganda, with prominent Nazi leaders, including Hitler, participating in the parades and ceremonies.

\section{References}

Barthes, Roland (1993): Camera Lucida: reflections on photography. London: Vintage.

Batchen, Geoffrey, (2008): “Snapshots”, Photographies 1, 2: 124, 121-142.

Becker, Karin (1992): "Picturing our past. An Archive Constructs a National Culture", The Journal of American Folklore, 105: 415, pp. 3-18.

Burke, Peter (2001): Eyewitnessing: the uses of images as historical evidence. Ithaca, N.Y.: Cornell University Press.

Dahlgren, Anna (2013): Ett medium för visuell bildning: kulturhistoriska perspektiv på fotoalbum 1850-1950. Göteborg: Makadam.

Durkheim, Émile (1952): Suicide. London: Routledge and Kegan Paul.

Dayan, Daniel \& Katz, Elihu (1992): Media events: the live broadcasting of history. Cambridge, Mass.: Harvard University Press.

Kirkegaard, Søren (1848): Journals IV 164

Lööw, Heléne (2004). Nazismen i Sverige 1924-1979: pionjärerna, partierna, propagandan. Stockholm: Ordfront.

Manson, Rhiannon \& Sayner, Joanne (2018): Bringing museal silences into focus: eight ways of thinking, International Journal of Heritage Studies. 10: 1, 1-16.

Sandbye, Mette (2014): "Looking at the family album: a resumed theoretical discussion of why and how", Journal of Aesthetics \& Culture, 6: 1, 1-16.

Sekula, Allan (2003): "Reading an archive. Photography between labour and capital", Liz Wells (ed.) The photography reader, London: Routledge, 443-452.

Strandroth, Cecilia (2009): "Pà resande fot i det digitala bildarkivet: ett brukarperspektiv," Pelle Snickars \& Anna Dahlgren (eds), I bildarkivet: om fotografi och digitaliseringens effekter, Stockholm: Kungl. Biblioteket, 91-120.

Taylor, Joel, and Laura Kate Gibson (2017): "Digitization, Digital Interaction and Social Media: Embedded Barriers to Democratic Heritage." International Journal of Heritage Studies 23: 5, 1-13. 